\title{
Studying from Home? Do Private and Public Benefits Go Side by Side?*
}

\author{
George Agiomirgianakis ${ }^{1 *}$, Georgios Bertsatos ${ }^{2}$, Fay Makantasi2, \\ Athanasios Mihiotis ${ }^{3}$, Nicholas Tsounis ${ }^{1,4}$
}

${ }^{1}$ Economic Analysis and Policy Lab, School of Social Sciences, Hellenic Open University, Patras, Greece

${ }^{2}$ Department of Economics, School of Economic Sciences, Athens University of Economics and Business, Athens, Greece

${ }^{3}$ School of Social Sciences, Hellenic Open University, Patras, Greece

${ }^{4}$ Department of International Trade, Technological Institute of Western Macedonia, Kastoria, Greece

Email: `gmagios@eap.gr, bertsatosg@aueb.gr, faymakantasi@aueb.gr, mihiotis@eap.gr, tsounis@kastoria.teiwm.gr

How to cite this paper: Agiomirgianakis, G., Bertsatos, G., Makantasi, F., Mihiotis, A. and Tsounis, N. (2018) Studying from Home? Do Private and Public Benefits Go Side by Side? Modern Economy, 9, 1423-1438. https://doi.org/10.4236/me.2018.98090

Received: July 9, 2018

Accepted: August 7, 2018

Published: August 10, 2018

Copyright $\odot 2018$ by authors and Scientific Research Publishing Inc. This work is licensed under the Creative Commons Attribution International License (CC BY 4.0).

http://creativecommons.org/licenses/by/4.0/ (c) (i) Open Access

\begin{abstract}
The objective of this paper is to compare the average annual and total cost of obtaining a university degree in three different universities: an Open and Distance Learning university serving lifelong learning purposes and two conventional universities in Greece. Our findings show substantial differences in average annual costs (per student) among these three universities with the Open and Distance Learning University (Hellenic Open University-HOU) having both the lowest annual average private and university cost. Consequently, HOU has the lowest average social cost. Moreover, comparing the total private cost for obtaining a university degree, the lowest cost is in the HOU despite its longer period of studies. This raises expectation to perspective students of HOU for higher rates of return after graduation. A similar pattern, also, holds for the social cost showing that HOU is socially cost effective. Clearly, our findings suggest that an Open and Distance Learning University that serves lifelong learning purposes is a cost effective investment in creating human capital privately and socially.
\end{abstract}

\section{Keywords}

Private Education Cost, Social Education Cost, Distance Learning Universities, Lifelong Learning, Traditional Universities

\footnotetext{
*Agiomirgianakis, Mihiotis, Makantasi and Tsounis acknowledge that this research was carried out as a research project co-financed by the European Union (European Social Fund-ESF) and Greek national funds through the Operational Program "Education and Lifelong Learning" of the National Strategic Reference Framework (NSRF). Financial support is gratefully acknowledged.
} 


\section{Introduction}

In this paper we compare the cost of studies between a distance learning university and two conventional universities in Greece. We distinguish two types of costs accrued by university studies: first, the financial costs incurred by students and their parents representing the private cost of studies and second, the financial costs undertaken by a university due to its operation and thus named university cost. As private cost, we consider all personal expenses such as accommodation, food, maintenance, transport etc. that a student or his/her parents have to pay during his/her study. On the other hand, given that all universities in Greece are public universities mainly financed by the ministry of Education and partly financed by research funds raised through research projects, we define as university cost, the amount that a university spends per student from its own financial budget. The sum of private and university costs is defined as the third type of cost, the social cost of education per student.

For our analysis we have selected three universities: the Greek distance learning university, named the Hellenic Open University (HOU) and two traditional universities requiring physical presence of their students: the University of Macedonia (UOM) and the University of Crete (UOC). The selection of these traditional universities was based on two criteria: first, both universities are located in the Greek periphery, as HOU does, and second, these two universities are about the same size of HOU. To estimate student expenses (private cost) in the case of traditional universities we used a questionnaire survey. Questionnaires were filled in along a student interview in his/her university campus, while the interviews for HOU were carried out either via telephone, or by meeting students after appointment at a convenient to the student place in four different towns. The quantification of the university cost of studies was based on the official annual balance sheets that universities submit to the ministry of education. Subsequently, we compare private cost, university cost and the sum of them defined as the social cost of education for the average student in these three universities, as well as, the total cost of obtaining a university degree in each of the three universities.

The structure of this paper is as follows. Section 2, describes the methodology used for the quantification of student expenses i.e. private cost, it analyses the methodology for estimating both the university cost and the social cost per student in these three universities. All these costs are on annual basis. Furthermore, in this section, we also analyze the methodology for calculating total costs required to obtain a degree in each of the three universities depending upon the different years of studies that may be required in each one of them. Section 3, presents the sample description as well as the data set. Section 4, contains the empirical results. Finally, Section 5 summarizes our paper and spells out the policy implications of our findings.

\section{Methodology}

As we mentioned above, we have used a questionnaire survey in order to obtain 
data for the private cost of studies in UOM and UOC. Section 3, below presents the sample description as well as the data collected for the two traditional universities. It should be noted, however, that the private cost incurred by $\mathrm{HOU}$ students is different to the one incurred by students of the two traditional universities. Indeed, HOU students do not have to rent a house near their university because the distance learning methodology employed by HOU, allows them to follow their studies while remaining in their home city. However, HOU students have to pay tuition fees for their studies, some travel expenses and possibly some hotel overnight costs in order to attend either their Group Advisory Meetings (GAM) or by moving into their examination centers.

Data on annual average tuition fees per HOU student were selected from the Rector's office and Finance department of this university. Students of HOU are considered either active or registered. Active students are those who attend a module and pay their tuition fees while the registered students are defined as those who are allowed to attend to module but they do not actually attend it in a current academic year. Consequently, we use only the number of active students for the calculation of annually average private cost of studies per student.

As we mentioned above, in the calculation of the private cost for HOU, besides the tuition fees, we include the students' travel costs incurred for attending their GAMs and participating in their final and resit exams. To this end, we first, calculate the average number of courses declared by students in a year and the students' attendance in the GAMs. Second, we find the average percentage of students that have to travel in order to attend their GAMs and exams according to their residence area and the area where GAMs and the two exams (final and resit) take place. We describe the calculation methodology of the annually total cost of studies in the next section.

Except the tuition fees and the travel costs, HOU students also incur some other expenses for their studies such as private extra tutorial classes for the preparation of their assignments and their exams. Data for these expenses are derived from the survey regarding the HOU graduates described in Section 3. Finally, in the calculation of the HOU students annual cost of studies, we add the amount of $€ 100$, which includes the consumables (computers and stationeries). We consider this amount an ad hoc one. However, the questionnaire survey in the case of traditional universities students shows that the consumables are equal to the amount of $€ 100$. We assume that there is no difference in this type of expenses between HOU and traditional university students.

For the calculation of the annual university cost per student we used data of the finance department and the Rector's offices of the three examined universities.

Finally, in order to calculate the total private cost of obtaining a university degree we used the actual number of studying years required for completion of studies in each of the three universities, these data were obtained from the Rector's office and Finance department of each university. 


\section{Data Description}

The data set for the private cost of studies was collected with a questionnaire survey in the two traditional universities i.e., UOM and UOC. For UOM the survey took place in Thessaloniki while for UOC in the two campuses of the university i.e., Heraklion and Rethymnon.

The size of a sample according to international literature should be over $2.5 \%$ of the population [1]. ${ }^{1}$ To determine the size of our sample we used secondary data for students' population obtained from the Rector's office in UOM and UOC. Specifically, we collected 302 completed questionnaires from UOM and 349 school-clustered completed questionnaires from UOC. This school clustering is necessary in the case of UOC as this university has five schools with different education objects, different normal periods of university education and it is located in two towns with different cost of living. The schools of UOC are: School of Philosophy, School of Education, School of Social, Economic \& Political Sciences, School of Sciences and Engineering, and School of Medicine. The first three schools are located in Rethymnon, while the rest are located in Heraklion. We make the reasonable assumption that student expenses may vary by school, first because students of different schools are expected to have different socioeconomic characteristics that could differentiate their expenses and second, the cost of living may be different in the two towns that UOC operates i.e. Heraklion and Rethymnon. On the other hand, school clustering sample is not necessary in the case of UOM because its schools have similar education object (social sciences), same normal period of university education and are located in the same place, i.e., Thessaloniki.

The questionnaire survey was carried on from 15/09/2014 to 20/09/2014 in Crete. Specifically, in Heraklion on 16, 18-20/09/2014 and in Rethymnon 15 and 17/09/2014. In Thessaloniki the corresponding dates were 23/09/2014 to 27/09/2014. We gathered 44, 86, 70, 113 and 36 questionnaires from School of Education, School of Social Economic \& Political Science, School of Philosophy, School of Sciences and Engineering, and School of Medicine students, respectively. The corresponding population covering percentages are $2.56 \%, 2.56 \%$, $2.62 \%, 2.57 \%$ and $4.9 \%$. Regarding School of Medicine students, the sample is more than double of the respective ones of the other schools because there is a significantly smaller number of students in the School of Medicine relative to the other schools. Particularly, the minimum number of questionnaires should be 30. The total questionnaires filled in for UOC are 349. The corresponding number for UOM is 302 , i.e., $3.78 \%$ of population. ${ }^{2}$ Section 4 covers the questionnaire survey results of private cost of studies in the three universities examined.

The data set on the private costs of HOU students was derived from a Hellenic Open University (HOU) research project co-financed by the European Union (European Social Fund-ESF) and Greek national funds through the Operational ${ }^{1}$ The Hellenic Statistical Authority (ELSTAT) uses a sample equal to $2 \%$ of the population regarding large population surveys.

${ }^{2}$ The active number of UOM students in 2013 was 7993 
Program "Education and Lifelong Learning" of the National Strategic Reference Framework (NSRF). The survey period was from June to October 2015 and 712 questionnaires of first degree HOU graduates were completed, i.e., $4.5 \%$ of population. $^{3}$

For the calculation of university cost, social cost of studies per student and the number of active students, we used data of the Finance department from each of the three examined universities. In the next Section 4, we present the results related to these types of costs.

\section{Cost of Studies Results}

\subsection{Private Cost Results in UOM and UOC}

Table 1 shows the results of our questionnaire survey regarding the student

Table 1 . The annually average sector expense of students in UOM and UOC.

\begin{tabular}{|c|c|c|c|}
\hline$\#$ & Sector & $(€)$ UOM & $(€)$ UOC \\
\hline 1 & Food, Beverages and Tobacco & 445 & 771 \\
\hline 2 & Clothing & 308 & 134 \\
\hline 3 & Firewood & 0 & 2 \\
\hline 4 & Paper and paper products & 27 & 65 \\
\hline 5 & Computers and electrical devices & 79 & 27 \\
\hline 6 & Electric power and gas & 24 & 15 \\
\hline 7 & Furniture & 32 & 12 \\
\hline 8 & Electric power and gas & 252 & 229 \\
\hline 9 & Heating oil & 9 & 10 \\
\hline 10 & Water supply and drainage & 33 & 84 \\
\hline 11 & Road and rail transports & 363 & 333 \\
\hline 12 & Ship transports & 3 & 68 \\
\hline 13 & Air transports & 23 & 45 \\
\hline 14 & Tourist agencies & 3 & 14 \\
\hline 15 & Post Office and courier service & 1 & 1 \\
\hline 16 & Rent & 1031 & 2499 \\
\hline 17 & Fast food & 324 & 299 \\
\hline 18 & Print & 16 & 44 \\
\hline 19 & Theater and movies & 39 & 12 \\
\hline 20 & Landline and mobile phones & 184 & 150 \\
\hline 21 & Education services & 128 & 17 \\
\hline 22 & Health services & 20 & 4 \\
\hline 23 & Entertainment, library, museums and gambling (including OPAP) ${ }^{\mathrm{a}}$ & 1185 & 840 \\
\hline 24 & Gym and athletics & 75 & 90 \\
\hline 25 & Computers and electrical devices services & 1 & 1 \\
\hline 26 & Retail trade & 402 & 542 \\
\hline & Annual total & 5006 & 6306 \\
\hline
\end{tabular}

${ }^{a}$ OPAP is the Greek Organization of Football Prognostics S.A. and operates in numerical lotteries and sports betting. Source: Questionnaire survey and authors calculations.

${ }^{3}$ The active number of HOU students in 2013 was 15,768 . 


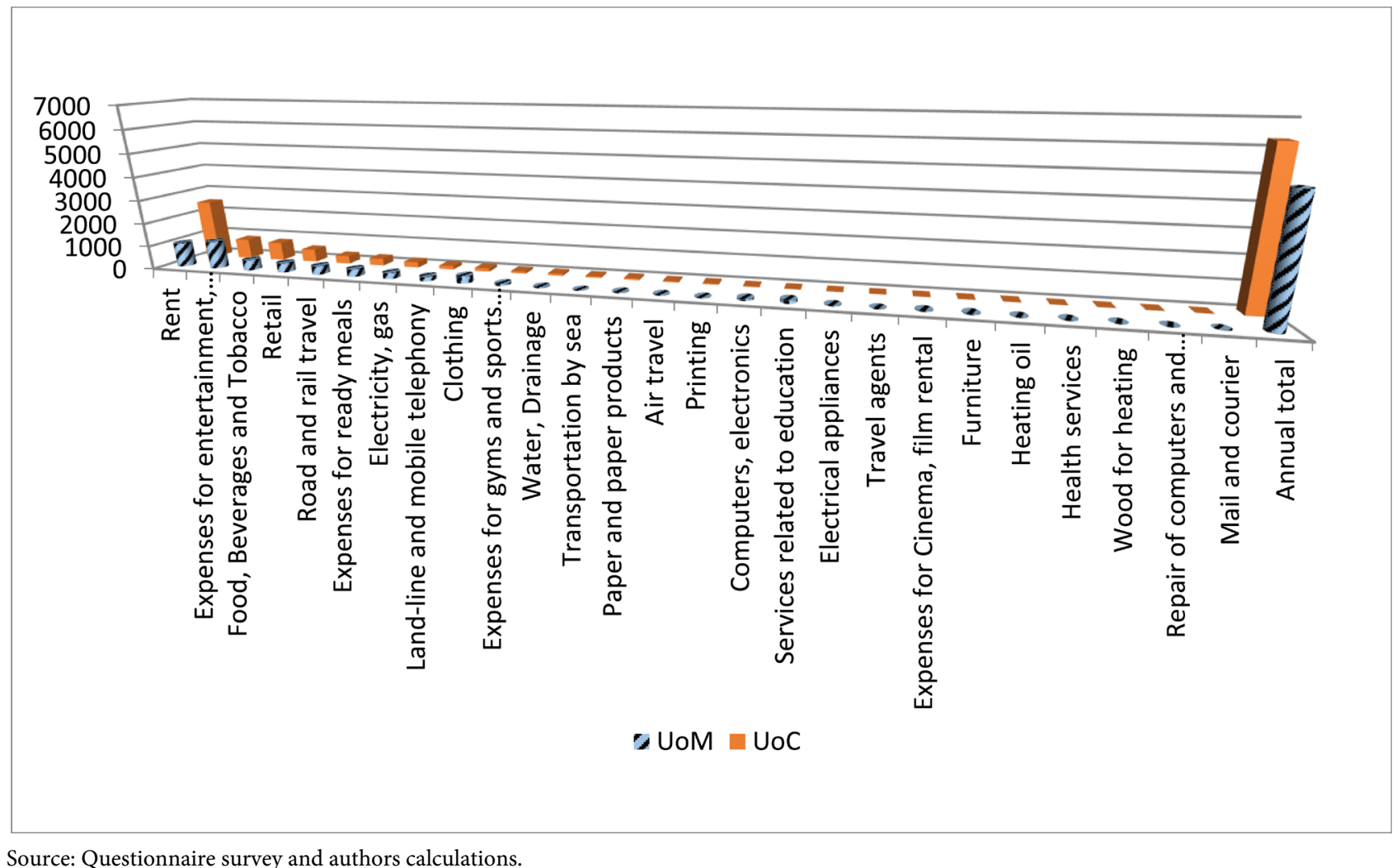

Source: Questionnaire survey and authors calculations.

Figure 1. Annual average expenses of students in UOM and UOC, by sector.

expense in UOM and UOC in columns three and four, respectively (these can also be seen in Figure 1). For UOM each number is the arithmetic average per sector, while for UOC, each number is the weighted average per sector. ${ }^{4}$ The sectors included in the questionnaire are the standard sectors of economic activity used by the Eurostat NACE rev.2 classification [2].

We see that the first sector in annually expenses for UOM is entertainment, library, museums and gambling (including OPAP) with $€ 1185$ followed by rent with $€ 1031$. Food, beverages and tobacco, road and rail transports, fast food and clothing have a significant share in the total expenses for UOM students. For UOC, we have almost the same results. Though, the first sector is rent with $€ 2499$ and then comes entertainment, library, museums and gambling (including OPAP) with €840. Also, food, beverages and tobacco, and clothing have a great share in the total expenses. One notable difference between UOM and UOC is the amount spent for sea transports. It is the $1 \%$ of total expenses for UOC students, while it is almost insignificant for UOM students. Figure 1 below is an alternative way of reading Table 1 .

Figure 2 below displays the shares of each sector in the total expenses. Sectors with less than $€ 50$ are categorized as "Other sectors".

The sectors that have a small share in the total student expenses, in both Universities, $(<0.5 \%)$ are those of heating oil, health services, firewood, computers

${ }^{4}$ We justify the use of school-clustered sampling in UOC in Section 3. 

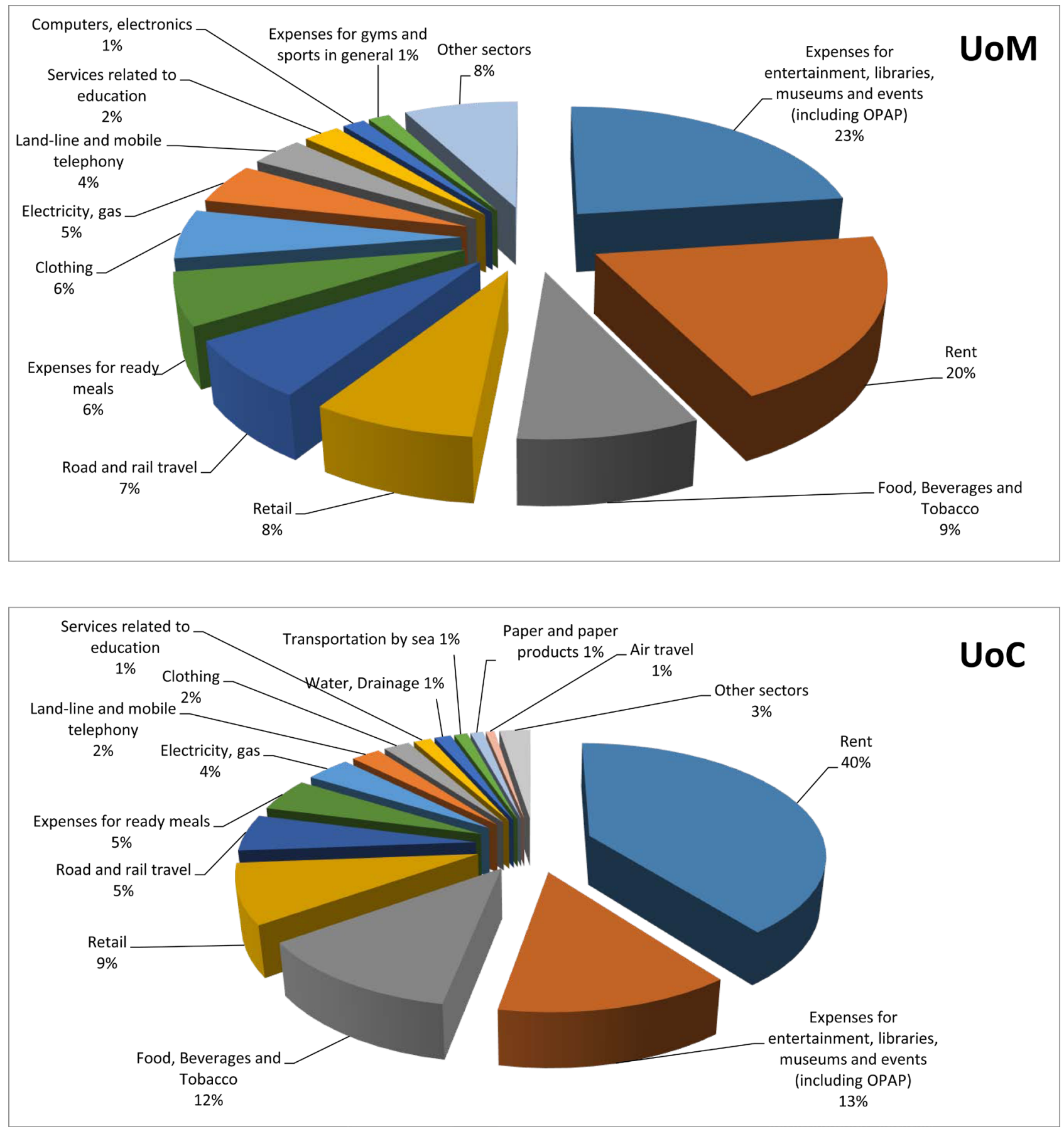

Source: Questionnaire survey and authors calculations.

Figure 2. Sector-clustered student expenses for UOM and UOC.

and electrical devises services, and P.O. and courier service.

We see that UOC students spend $€ 1300$ more than UOM students. Therefore, we need to test the means equality hypothesis, i.e. $H_{0}: \mu_{1}=\mu_{2} ; \mu_{1}, \mu_{2}$ is the mean of expenses for the population of students in UOC and UOM, respectively. The alternative hypothesis is $H_{1}: \mu_{1} \neq \mu_{2}$. We use $t$-test according to Welch [3], to test the hypothesis that the means of student expenditure differ between the 
two Universities. It is expected that the means of student expenditure differ between UOM and UOC because 11) the student in the two universities present different social economic characteristics and thus, their expenses differ and 2) UOC has a Medical School, whereas UOC does not.

The test statistic was calculated from $t=\frac{\left(\overline{X_{1}}-\overline{X_{2}}\right)-0}{\sqrt{S_{\overline{X_{1}}-\overline{X_{2}}}^{2}}}$, where $S_{\overline{X_{1}}-\overline{X_{2}}}^{2}=\frac{S_{1}^{2}}{n_{1}}+\frac{S_{2}^{2}}{n_{2}}$ and $S_{1}^{2}, S_{2}^{2}$ are the sample variances, $n_{1}=349, n_{2}=302$ are the sample sizes, and $\overline{X_{1}}=6306, \overline{X_{2}}=5006$ are the sample means of student expenditure, where the subscript 1 corresponds to UOC and subscript 2 to UOM.

We found the value of $t$-statistic to be 5.86 . Thus, the null hypothesis of means equality is rejected at a less than $1 \%$ level of statistical significance. So, we conclude that the expenses of UOC are greater than those of UOM, and consequently, that the annual average private cost of studies per student is larger in UOC.

This difference between the annual average student expenses between UOM and UOC can be primarily explained by the rent expenses, which are $€ 1468$ higher for UOC students. Indeed, the rentals in the cities of Heraklion and Rethymnon are higher than those in Thessaloniki. One possible reason is the greater number of tourists in Heraklion and Rethymnon, and thus, house supply is relatively shorter due to the small size of these cities. One other factor, which explains the difference in the student expenses between UOM and UOC is that $12 \%$ of UOM students (the corresponding number for UOC is $1 \%$ ) do not rent a house near the university. Namely, these students live with their parents in their place of residence in Thessaloniki or they move to Thessaloniki just for the exams (attending class in UOM is not obligatory).

\subsection{Private Cost Results in HOU}

As we mention in Section 2, the private cost of HOU students displays different characteristics than that of UOM and UOC students. Students do not incur rent expenses as they do not change their place of residence due to their studies because of the distance learning methodology of HOU. However, HOU students need to pay fees for their studies. Also, their expenses are augmented by the travel costs for attending their GAMs and participating in their final and resit exams.

HOU Rector's office and Finance department provided us the required data for the annual average tuition fees $(A R)$. We calculated the average of cost per student as:

$$
A R=C U \times A N C U
$$

where,

$C U$ is the cost per course for undergraduate programs,

$A N C U$ is the average number of courses taken in undergraduate programs.

The annual average tuition fees of HOU students is $€ 912.41$. However, in or- 
der to calculate the total private cost of studies we need to add the amounts corresponding to travel costs (so the HOU students can attend to GAMs and participate in their exams). So, we take into account the following:

1) Students that have to move and thus incur the travel costs, in order to attend to the GAMs and to the exams are those that do not live close to the places where GAMs and exams take place. Also, the number of students that live in a town different than that where GAMs and exams take place are 9092 in total.

2) We need to estimate the average number of travels per student according to GAMs. In undergraduate programs, 964 student groups in 81 modules have 5 GAMs annually while 135 student groups in 16 modules have 6 GAMs annually. ${ }^{5}$ Hence, the weighted average of GAMs is 5.12 (NUOSS). The weighted average of participating in every GAM is $62.4 \%$ ( $P A R T O S S U$ ).

3) Every student that lives in a town different from the location of his/her GAMs has to travel in order to participate in his/her exams, while only $50 \%$ of these students have to travel for the resit exams. ${ }^{6}$

4) We estimate that the travel cost required to participate in GAMs and exams is about $€ 130$ including cost of travel, rest and living. For undergraduate students that travel from abroad (FTU) the travel cost is about $€ 350$.

$A T R A V C=\frac{(D T U \times S T U \times N U O S S \times P A R T O S S U \times 130)+[(D T U \times S T U \times 130)+(F T U \times 350)] \times 1.5}{T U}$

where,

ATRA VC: the average cost of travelling per year and per student in HOU,

$T U$ : the total number of undergraduate students,

FTU: the number of undergraduate students living abroad,

$D T U$ : the number of undergraduate students living in Greece, $D T U=T U-$ FTU,NUOSS: the number of GAMs in undergraduate programs,

$S T U$ : \% of traveling undergraduate students

PARTOSSU: \% of undergraduate students participating in GAMs

According to the $A T R A V C$ formula, the average cost of travelling per year and per student in HOU is equal to $€ 199.55$. $^{7}$

Besides the tuition fees and cost of travelling, HOU students incur some other costs for their studies. The major cost is the expenses accrued by the tutorial classes required for the preparation of assignments and exams. The data for the tutorial classes' costs was extracted from the questionnaires of the survey regarding the HOU graduates (see Section 3 for a description of the HOU survey). The weighted average of tutorial classes is about $€ 1235$. This amount corresponds to annually average expense of $€ 182$. Furthermore, we assume that this amount remains the same in 2013, since this survey was carried on the ${ }^{5}$ Each module has a number of student groups is several cities, depending on the total number of students registered for the module.

${ }^{6}$ The final exam pass rate is about $50 \%$, while the total pass rate is around $70 \%$. Thus, every student has to move 1.5 times for the exams due to living in a different county.

${ }^{7}$ The first term in the RHS of ATRAVC formula, captures HOU students that are in Greece and they move regularly to their GAMs, while the second term captures HOU students moving to their exams' centers either within Greece or from abroad. 
2007-2009 period. We have to make this assumption because the rest of the sample regarding the other types of costs has a base year, 2013.

Moreover, we have to add the amount of $€ 100$ in order to find the total annual HOU student expense. This surcharge includes the consumables (computers and stationeries) and we consider it ad hoc. However, this amount is the same as that of traditional-university students, which we assume that have the same needs with the HOU students.

Finally, should we take into consideration all of the above, the total private cost of HOU students is approximated to be $€ 1394$. Specifically, its components are: $€ 912.41$ for tuition fees, $€ 199.55$ for movement costs required to participate in GAMs and exams, $€ 182$ for tutorial classes and $€ 100$ for consumables (computers and stationeries).

\subsection{University Cost and Social Cost Results in UOM, UOC and HOU}

The Finance department and Rector's Office of UOM and UOC, provided us the data required to calculate the university cost of studies. Namely, the expenses of each university for its students, and the number of active students. The active number of students is the number of students whose current education year is equal or less than the average number of years required to obtain a degree augmented by two years. Also, the active students are those who have access to the student provisions system (books, supported material, medical care etc.). In HOU, active students are those who attend a module and pay fees (each programme of study consists of annually modules each one corresponding to three semester courses of conventional universities), while the registered students are defined as the students who are allowed to attend a module but they do not actually attend it in the current academic year. Consequently, we use only the number of the active students for the calculation of annually average cost of studies per student.

In calculating the total university cost we have included expenses regarding research financing by the state or private entities. The Universities Special Account for Research Funds manages these funds. ${ }^{8}$ Research funds are important because they show the creation of new knowledge as well as the absorption capacity of advanced knowledge created elsewhere. ${ }^{9}$ So, research in progress in one university affects teaching quality offered by that university and thus, research funds should be taken into account when calculating university cost of studies.

Regarding HOU university cost of studies, we have used the respective balance sheets. The total HOU expense per student is $€ 1024.84 .{ }^{10}$ From this amount we have to subtract the amount related to tuition fees i.e., €912.41 (see above subsection Private cost results in HOU) that is a part of the university's budget but it is calculated here under the "private cost" of studies. Therefore, the total univer-

\footnotetext{
${ }^{8}$ This Special Account for Research Funds is called ELKE in Greek. ${ }^{9}$ See Feldman [4], Lundvall et al. [5], Koo [6] and Bassiakos et al. [7].

${ }^{10} \mathrm{HOU}$ budget is $€ 20,508,598.89$ (net amount excluding third party cash inflows and outflows), ELKE's expenditure is $€ 9,565,822.13$ and public investments program's expenditure (for buildings maintenance) is $€ 104,075.02$.
} 
sity cost of studies per HOU student is $€ 112.43$.

Table 2 displays the university cost of studies per student for the three universities examined, i.e. UOM, UOC and HOU.

We observe that the university cost of studies per student and year is significantly larger in UOC then UOM follows with HOU being the last one. These results are expected as UOC has a Medical School and according to international cost indices [8], the operation of a Medical School costs seven times more than that of other Schools that do not have laboratories. Thus, the existence of labs explains the increased university cost in UOC. Also, UOC has campuses in two cities, while UOM has campuses only in one place. HOU has the lowest university cost of studies because its students have to pay tuition fees, which cover a great deal of the total university expenses. Also, the distance learning methodology contributes to a further reduction of university expenses (Deming et al., 2015).

The calculation of the social cost per student is obtained from the summing up of private and university costs of studies per student and year. Table 3 shows the three types of cost (private, university and social) per student for each of the three universities examined.

We observe that UOM private cost (PC) is 3.59 times larger than that of HOU, while UOC private cost is 4.52 times larger than that of $\mathrm{HOU}$ (i.e., $\mathrm{PC}^{\mathrm{UOM}}>3.59$ $\mathrm{PC}^{\mathrm{HOU}}$ and $\left.\mathrm{PC}^{\mathrm{UOC}}>4.52 \mathrm{PC}^{\mathrm{HOU}}\right)$. UOC has the largest private cost of studies per student. The difference in private cost between UOC and UOM is mainly due to the higher house prices in Crete. Furthermore, UOC university cost (UC) is 6.94 times larger than that of UOM, $\left(\mathrm{UC}^{\mathrm{UOC}}>6.94 \mathrm{UC}^{\mathrm{UOM}}\right)$ as the existence of the Medical School in UOC is the major reason of this gap. In comparing social costs (SC) of studies, the UOC cost is 6.24 and 3.63 times larger than the corresponding social cost of HOU and UOM, respectively, $\left(\mathrm{SC}^{\mathrm{UOC}}>6.24 \mathrm{SC}^{\mathrm{HOU}}\right.$ and $\left.\mathrm{SC}^{\mathrm{UOC}}>3.63 \mathrm{SC}^{\mathrm{UOM}}\right)$. Finally, UOC operates with 1.72 times larger social cost of

Table 2. University cost of studies in UOM, UOC and HOU.

\begin{tabular}{cc}
\hline Universities & Annual university cost of studies per active student $(€)$ \\
\hline UOM & 455.58 \\
UOC & 3093.25 \\
HOU & 112.43 \\
\hline
\end{tabular}

Source: Universities' Economic Agencies and Rectors' offices. Authors calculations.

Table 3. Private, University and Social cost of studies per student and year.

\begin{tabular}{cccc}
\hline Cost of studies Universities & Private cost $(€)$ & University cost $(€)$ & Social cost $(€)$ \\
\hline UOM & 5006 & 445.58 & 5461.58 \\
UOC & 6306 & 3093.25 & 9399.25 \\
HOU & 1394 & 112.43 & 1506.43 \\
\hline
\end{tabular}

Source: Universities' Economic Agencies and Rectors' offices. Authors calculations. 
studies per student compared to UOM.

Concluding this section we may say that private, university and social costs of HOU are the smallest compared to other two traditional universities.

\subsection{Total Cost of Studies Required to Obtain a Degree}

We turn now into calculating the total cost of obtaining a university degree in these three universities. Besides the yearly cost of studies per student we, also, need to know the average duration required for completion of studies in each university. Table 4 below presents these numbers.

We find that HOU average duration of studies is indeed higher than that of UOM and UOC because most of the HOU students are part time matured students. They work during their studies and most of them have families. The lack of time is greater for them compared to traditional universities students due to family obligations, work obligations and social activities, thus, study attendance, studying time and the exams pass rates are relatively lower for HOU students. Yet, in UOM and UOC, the actual average number of years required to obtain a degree is greater than the standard required number of years. Katsikas et al. (2011) find no evidence of a strong correlation between the social economic characteristics of UOM students and the number of years studying or with their performance. Hence, we may consider that the institutional framework of Higher Education studies in Greece plays a significant role to the divergence between the actual and the expected number of years required to obtain a degree. Based on Table 3 and Table 4, we can calculate the total amount invested by the society as a whole for a student of UOM, UOC and HOU. Also, they show the respective amount regarding the private and university cost.

In Table 5, we observe that the HOU social cost of studies required to obtain a degree is the lowest among all costs. Specifically, it is 2.5 and 4.72 times smaller

Table 4. Average number of years required to obtain a degree.

\begin{tabular}{cc}
\hline Universities & Years \\
\hline UOM & 5.4 \\
UOC & 5.9 \\
HOU & 7.8 \\
\hline
\end{tabular}

Source: Universities Rector's office and Finance department. Authors calculations. Note: Results concerning UOM and UOC average duration of years required to obtain a degree are available upon request.

Table 5. Total cost of studies ( social cost) required to obtain a degree.

\begin{tabular}{cccc}
\hline University & Private cost $(€)$ & University cost $(€)$ & Social cost $(€)$ \\
\hline UOM & $27,032.40$ & $2,406.13$ & $29,438.53$ \\
UOC & $37,205.40$ & $18,250.18$ & $55,455.58$ \\
HOU & $10,873.20$ & 876.95 & $11,750.15$ \\
\hline
\end{tabular}

Source: Authors calculations based on questionnaires survey and Universities' Economic Agencies and Rectors' offices data. 
than the respective costs in UOM and UOC. Yet, the HOU private cost of studies required to obtain a degree is 2.49 and 3.42 times lower than those of UOM and UOC respectively. From the graduates' point of view and taking into account the equivalence of degrees, along similar scientific disciplines between traditional universities and $\mathrm{HOU}$, one could expect that the rate of return attributed to a degree from HOU could potentially be much higher than the rates of return that graduates of the other two universities could earn due to the lower total cost of studies in HOU. This is in accordance with the finding of Agiomirgianakis et al. [9] who show, by using a Mincer type model, that the rate of return to investment in education for HOU undergraduates is about 4 times higher than that of undergraduates of traditional Universities in Greece. This rate is about double for the Master's degree graduates. Also, HOU university cost is 2.74 times lower than the corresponding cost in UOM, whereas it is 20.8 times smaller than the respective cost in UOC.

The reasons that HOU displays significantly lower total cost of studies required to obtain a degree is because of two reasons, first, the lower private cost relative to the corresponding value of the traditional universities as HOU students do not have to move away from their home due to their studies and second, the usage of distance learning methodology considerably reduces the university cost of studies per student. The presented results are in accordance with international literature, which suggests that the distance learning methodology reduces considerably the cost required to obtain a degree [10]. ${ }^{11}$

\section{Conclusions}

The objective of this paper is to compare the cost of studies between a distance learning university and two conventional universities in Greece. We distinguish two types of costs accrued by university studies: first, the financial costs incurred by students and their parents representing the private cost of studies and second, the financial costs undertaken by a university due to its operation and thus named university cost. As private cost, we consider all personal expenses such as accommodation, food, maintenance, transport etc. that a student or his/her parents have to pay during his/her study. On the other hand, given that all universities in Greece are public universities mainly financed by the Ministry of Education and partly financed by research funds raised through research projects; we define as university cost, the amount that a university spends per student from its own financial budget. The sum of private and university costs is defined as the social cost of education per student.

We quantify the private costs of studies in three universities: the Greek distance learning university named the Hellenic Open University (HOU) and two traditional universities requiring physical presence of their students: the University of Macedonia (UOM) and the University of Crete (UOC). The selection of these traditional universities was based on two criteria: first, both universities are

${ }^{11}$ In Greece, degrees obtained by HOU are considered equivalent to degrees of conventional universities and provide the same professional rights to their holders. 
located in the Greek periphery, as HOU does, and second, both universities are about the same size of HOU. To estimate student expenses (private cost) we used a questionnaire survey. In the case of traditional universities, questionnaires were filled in with a short student interview in his/her university campus, while the interviews for HOU were carried out either via telephone, or by meeting students outside HOU campuses. The quantification of the public cost of education was based on the official annual balance sheets that universities submit to the Ministry of Education. Subsequently, we compare private cost, university cost and the sum of them defined as the social cost of education for the average student in these three universities.

Our findings show substantial differences among these three universities with the distance learning university (HOU) having the lowest annual private average cost $(€ 1394)$ despite the fact that its students have to pay tuition fees. This lower annual private cost of studies in HOU stems from the fact that its students do not have to relocate their place of residence and thus they do not face expenses for rent and maintenance associated with their studies.

Comparing the private cost of studies of the other two traditional universities, we found that the UOM is having a lower annual average cost (€5006) compared to the UOC (€6306) or, equivalently saying, a UOC student has on average $€ 1300$ higher annual private cost than a UOM student. The difference in the private cost of studies between the two traditional universities which is statistically significant at any convenient significance level is due to the higher cost of rent incurred by UOC students.

Examining, next, the university costs of education, we found, once more, that HOU has the lowest cost per student $(€ 112.43)$ of the three universities. This finding is due to two reasons: first, the larger part of HOU expenses is covered by tuition fees and secondly, HOU uses the distance learning methodology which contributes further in the reduction of the cost of study [10].

Comparing the average university cost of studies of the two traditional universities, we found that the UOM is facing a much lower annual cost (€455.58) compared to UOC (€3093.25). This difference between UOC and UOM stems partially by the fact that UOC has a Medical Faculty which, in turn, has high costs due to its laboratories. Indeed, the existence of a Medical Faculty in a University, according to international cost indicators is seven times higher compared to a faculty that does not include laboratories. Moreover, the UOC operates in two campuses in two different towns, namely in Heraklion and Rethymnon. These two reasons jointly result in a higher operational cost of the UOC compared to UOM which does not have labs and is located only in one town i.e., Thessaloniki.

Comparing, next, the annual social cost per student, invested by the society as a whole, in these three universities we found that HOU has the lowest average social cost $(€ 1506.43)$, followed by UOM (€5461.58) while UOC has the highest social cost of all (€9399.25). 
We turn next our analysis into quantification of the total cost of obtaining a degree in these three universities. To this purpose, we have in addition to annual expenses (private, university and social) to take into account also the duration of studies in each university. The actual average number of years for completion of studies in the HOU is in general higher than corresponding years of studies in the traditional universities. This could be explained by the fact that the majority HOU students are part time students who work during their studies and/or are having families. Both factors result in a lower available time for studies and thus leading to a relatively prolonged duration of studies relative to other two universities. Also, since UOC is having a medical school that requires a longer duration of studies has on average a longer period of studies relative to UOM. Therefore, we estimate that private costs for obtaining a degree are $€ 10,873.20$ for HOU; $€ 27,032.40$ for UOM and $€ 37,205$ for UOC. While the social cost for obtaining a degree in the three universities is $€ 11,750$ for $\mathrm{HOU}$; $€ 29,439$ for UOM and $€ 55,456$ for UOC. Comparing these results we can say that to obtain a HOU degree, a student has 2.49 times lower private cost than obtaining a degree in UOM and 3.42 times lower private cost than that in the UOC. From the point of view of perspective students, the much lower private cost of HOU degree has raised expectations for higher rates of returns after graduation. This is a reason for the popularity of HOU degrees denoted by the large numbers of applicants to HOU programs in the past 18 years.

A similar pattern holds for the cost of society as a whole. In particular, the social cost of obtaining a degree in the HOU is 2.5 times lower than that in the UOM and 4.72 times lower than that in the UOC.

The reasons that lead to this lower average private, university and social costs of HOU are, first, because changing place of residence is not required by the HOU and secondly, the use of distance-learning technologies considerably reduces the state cost of education per student.

Clearly, the policy implications of our findings suggest that a distance learning university serving lifelong learning purposes is a cost effective investment in creating human capital, both, privately and socially. In an era of tight budgetary conditions faced both by governments and households, investment in university distance learning programs leading to a university degree, might be a useful tool of financial consolidation that public authorities, as well as, perspective students might have to pursue.

\section{Conflicts of Interest}

The authors declare no conflicts of interest regarding the publication of this paper.

\section{References}

[1] Bartlett, J.E., Kotrlik, J.W. and Higgins, C. (2001) Organizational Research: Determining Appropriate Sample Size for Survey Research. Information Technology, 
Learning, and Performance Journal, 19, 43-50.

[2] Eurostat (2008) NACE Rev. 2. Statistical Classification of Economic Activities in the European Union. Office for Official Publications of the European Communities, Luxembourg.

[3] Welch, B.L. (1947) The Generalization of "Student's" Problem when Several Different Population Variances are Involved. Biometrica, 34, 28-35.

[4] Feldman, M.P. (2000) Location and Innovation: the New Economic Geography of Innovation, Spillovers, and Agglomeration. In Clark, G.L., Feldman, M.P. and Gertler, M.S., The Oxford Handbook of Economic Geography, Oxford University Press, Oxford, 373-394.

[5] Lundvall, B.-A. and Maskell, P. (2000) Nation States and Economic Development: from National Systems of Production to National Systems of Knowledge Creation and Learning. In: Clark, G.L., Feldman, M.P. and Gertler, M.S., The Oxford Handbook of Economic Geography, Oxford University Press, Oxford, 353-372.

[6] Koo, J. (2005) Technology Spillovers, Agglomeration, and Regional Economic Development. Journal of Planning Literature, 20, 99-115.

https://doi.org/10.1177/0885412205279796

[7] Bassiakos, Y., Tsipouri, L. and Tsounis, N. (2010) Competitiveness and Regional Development in Greece. International Journal of Financial Economics and Econometrics, 2, 81-96.

[8] Smith, T. (1992) Discipline Cost Indices and Their Applications. Research in Higher Education, 33, 59-70. https://doi.org/10.1007/BF00991971

[9] Agiomirgianakis, G., Lianos, T. and Tsounis, N. (2018) Returns to Investment in Higher Education: Is there a Difference between Distance Learning and Traditional Universities? Working Paper at Hellenic Open University.

https://www.eap.gr/images/stories/pdf/Agiomirgianakis_et_al._Returns_to_Investm ent_in_Higher_Education_July-2018.pdf

[10] Deming, D., Goldin, C., Katz, L.F. and Yuchtan, N. (2015) Can Online Learning Bend the Higher Education Cost Curve? Working Paper, Harvard University, Cambridge. 